\title{
Environmental Evaluation and Review of Rehabilitation of Soils After Oil Spills in Niger Delta
}

\author{
Edem $\mathrm{ID}^{1^{*}}$ and Nkereuwem $\mathrm{ME}^{2}$ \\ ${ }^{1}$ Department of Soil Science and Land Resources Management, University of UYO, Nigeria \\ ${ }^{2}$ Department of Soil Science, Federal University Dutse, Nigeria
}

Submission: April 05, 2017; Published: May 24, 2017

"Corresponding author : Edem ID, Department of Soil Science and Land Resources Management, University of UYO, Nigeria, Email: dennis.edem@gmail.com

\begin{abstract}
Very heavily polluted soils can be easily reclaimed by applying scientific principles but very light pollutions of the order of $1 \%$ or below which in actual fact may be beneficial to plant growth can be left for natural rehabilitation within 6 months and much higher concentrations of the order of $5 \%$ can easily be taken care of by farmers within the same period simply by the aeration effected by hoeing or cultivating the land. From the agricultural and scientific points of view, therefore, oil pollution is just a temporary setback to farming processes and just how temporary is determined by the level of pollution. Field work was carried out to review and identify the potentials and challenges facing the cleanup exercise. The results revealed that a measurement of the physical compaction revealed the critical value $>1.6 \mathrm{~g} \mathrm{~cm}^{-3}$ at the impacted areas, while, the point of spill and areas near water course were scaled as firm and extremely compacted respectively. On the other hand, the drainage pattern showed dominance of capillary pores on the surface to much aeration pores as it increased with depth. The value of permeability $\left(5.49 \mathrm{cmhr}^{-1}\right)$ on the $0-15 \mathrm{~cm}$ soil depth met the rapid discharge limit and acceptable range for ease of remediation process. Whereas, the lowest permeability value of $0.36 \mathrm{cmhr}^{-1}$ representing $143 \%$ reduction from subsurface recorded at depth greater than $60 \mathrm{~cm}$ was attributed to irregular (tortuous) pathways that increased with depth. Soil depths beyond $60 \mathrm{~cm}$ were seen to consistently superior to other depths for low permeability.
\end{abstract}

Keywords: Permeability; Rehabilitation ; Oil pollution; Soil attribute; Agriculture

\section{Introduction}

The soil is undoubtedly the most important basic natural resource of any nation. It is an irreplaceable natural resource and thus the need to conserves it. Therefore oil pollution very often generates a lot of emotional outburst [1]. Concerns over the effects of increasing oil spillage on land, streams, rivers and wetlands have mounted with time since oil prospecting started in Nigeria. Whatever the means of spillage, oil spillages resulting from oil well blow-outs and spillages from pipeline where oil is transported under high pressure are usually of a much higher magnitude especially if the spillage occurs is in a remote area where the spillage is not detected for a long time [2]. Oil has been considered as something foreign to the soil and the apparent longstanding adverse effects of oil from pipeline leaks or spillages from oil locations on crops and soils is of great concern to soil conservationist [3]. There is thus need to quickly rehabilitate oil polluted soils and get them back to normal. The impression has often been given that once oil heavily pollutes the land, it remains indefinitely. Our field and laboratory studies have revealed that certain changes that occurred on the soils' physical properties which control the bio-chemicals are attributable to the action of the rehabilitation in the Rumekpe's soils after oil spill. Looking at these soils from the mechanistic and agricultural standpoints, the investigation aimed at assessing the extent to which the total concentration of fluid (water, air and oil) enters the soil from the surface as a function depends of the distribution of the soils' physical characteristics down the soil profile.

\section{Materials and Methods}

\section{Description of study area}

The study was conducted in Port Harcourt. Port Harcourt is located in latitude $4049^{\prime} \mathrm{N}$ and longitude 6059' $\mathrm{E}$ in southeastern Nigeria, on the Bonny River, in the Niger Delta (Figure 1). The city is a leading port of the country, and a major industrial center. Port Harcourt has prospered as the regional headquarters for the petroleum industry. It has a large petroleum refinery and storage facilities. The local fishing industry is also important to the city's 
economy. Located in the city are the University of Port Harcourt (1975) and Rivers State University of Science and Technology (1971). While the Ijaw people are dominant in the region, the city itself is ethnically diverse. The port was established by the British in 1915 and serves eastern Nigeria and parts of northern Nigeria [4].

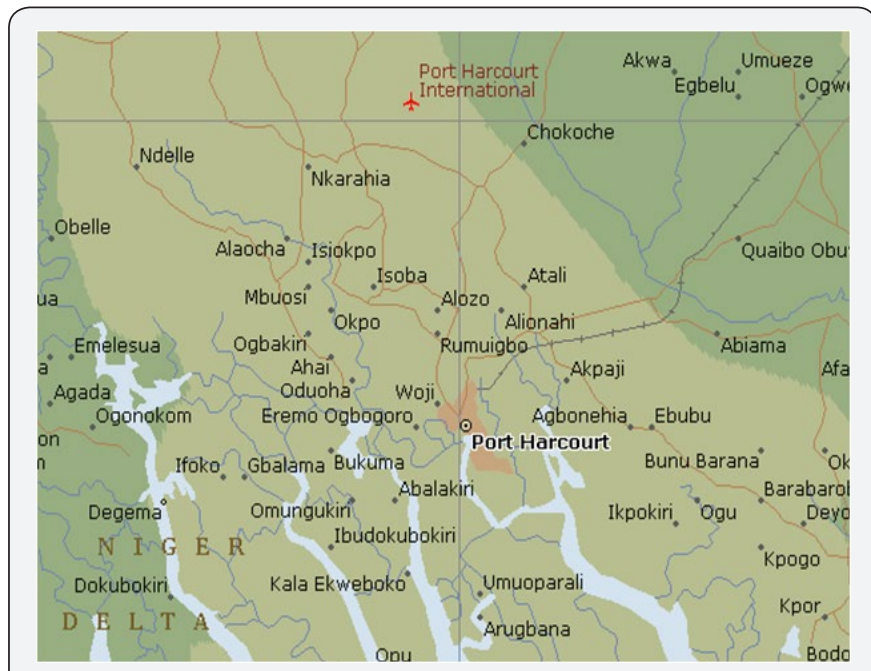

Figure 1: Showing the map of Port Harcourt.

\section{Climate}

Climatic condition of the area is characterized by two seasons, wet or rainy and dry season. The wet prolongs with a mean annual rainfall of $200 \mathrm{~mm}-300 \mathrm{~mm}$. the dry season commences from November lasting till February of march with an annual mean temperature of $26^{\circ} \mathrm{C}$ and $30^{\circ} \mathrm{C}$, highest temperature are experienced between January and February which coincides with over head of the sun with relative humidity varying from $70 \%$ to $80 \%$. The area is characterized by growth of shrubs, herbs and medium to tall trees, native vegetation, grasses and sometimes referred to as "derived savanna" [4]. They are highly susceptible to accelerated erosion.

\section{Soil sampling}

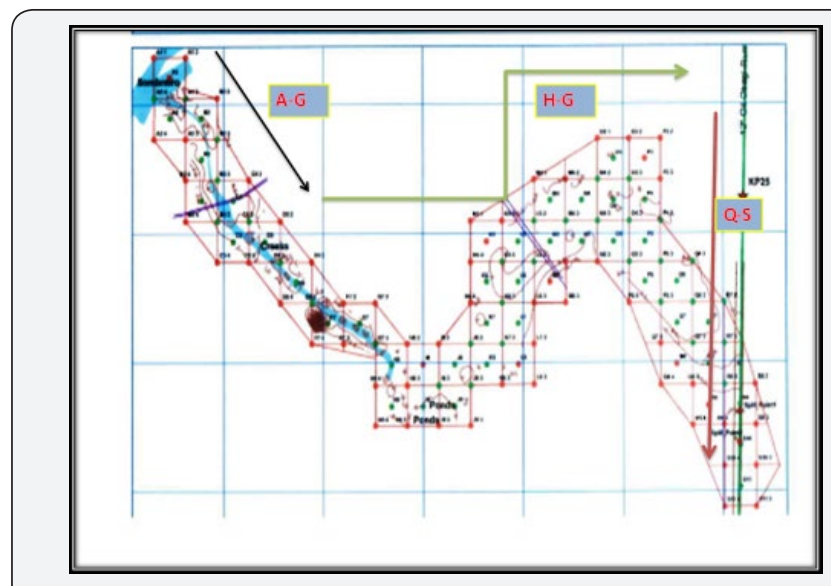

Figure 2 : Showing the trend of rehabilitated oil spill soils.
After three years of rehabilitation of soils after oil spill, bulk and core samples were collected at three (3) stratified areas christened: point of spill area on the right of way (Q-S), impacted points (H-P) and area close to water course (A-G) (Figure 2) two sampling depths of $0-15$ and $15-30 \mathrm{~cm}$ were properly demarcated. Samples were chained custody and properly preserved as described by [5] and a total of one hundred and forty-four (144) samples were collected and analyzed for various soil attributes.

\section{Sample preparation and statistical analysis}

Soil samples collected for particle size distribution analysis were properly air dried, crushed with plastic mortar and then made to pass through a $2 \mathrm{~mm}$ laboratory sieve then analyzed using Bouyoucos Hydrometer Method as described by [6]. Soil samples collected for aggregate stability were air dried and then made to pass through a $4 \mathrm{~mm}$ laboratory sieve and then analyzed using (Wet serving Technique) [7] Soil samples for Saturated Hydraulic Conductivity $\left(\mathrm{K}_{\text {sat }}\right)$ collected were saturated in water for $24 \mathrm{hrs}$ and then analyzed using (Constant-Head soil core method) [8]. Soil attributes were statistically analyzed with computer soft ware and results were graphically presented.

\section{Results and Discussion}

\section{Particle size distribution}

The range of particle size distributions in the soils tends to show an overall means of $67.22,10.93$ and $21.84 \%$ for sand, silt and clay respectively, at the points of spill. The adjacent control points recorded a typical range of total sand in soils of 53.3$3.3 \%$ with a mean of $63.3 \%$ and 10.2 (M4)-36.7\% (P4-3) of clay with a mean of $26.7 \%$. Silt content was consistently $10 \%$ in the control area. Rather than being one type or the other, these soils are a combination of sand, silt and clay with clear trend of high concentrations in sandy soils and low conductivity of water in soils with larger clay content.

On the surface soil, sand particles with fraction range between 45 and $60 \%$ were those at locations R7-3, P4-3, K7, L52, 04-3, A1-3, G7, L5 and S9. The amount of sand particles within the range of $61-69.0 \%$ were those of locations J8-3, L6, NS-3, Q6, S10, S11, B2-3, G7-3, HW, I9, J8, J8-2, K8, M5,05, 05-3, P4, P5, P53, P6, Q6-2,Q7 and Q7-3. On the other hand,

the locations with amount of sand fraction from $70 \%$ and above were those of A1-4, B2, B3, C4-3, E6, F7, H8, I8-3, K6, K7-3, L5-3, N4-2, N4-3, O3, O3-3, P6-3, R8-3, A2, B3-3, B4-3, C3, C4, D5, D5-3, E6-3, H9, J9, K6-3, L7, M4-3, N4, 04, R7-2 and R8. Whereas in the sub surface soil, sand content was consistently lower than the surface with the least contents of $36.7 \%$ (L5-3) and the highest amount of $66.7 \%$ recorded in locations A2, B2, B2-3, B33, D5, D5-3, G7, K7-3, P4 and S10. Compared with control soil that has $63.3 \%$. Sandy soils are more prone to drought and will quickly (within a few days) be depleted of their available water when evapotranspiration rates are high. 
Meanwhile, silt ranged from $10 \%$ on stations A1-3, A1-4, B2,B3, B2-3, C4-3, E6, R7-3, P4, K7, L5, L5-2, L6, 04-3, G7-3, G7, HW, I9, J8, J8-2, K8, M5, 05, 05-3, P4, P5, P5-3, P6, Q6-2, Q7, Q7-3, S9, J8-3, NS-3, Q6, Q6-3, S10, S11 to $18.7 \%$ on station Q7. Compared with subsurface status, silt content under B2, C4-3, G7-3, I9, J9, K7, 03, P4-3, and N4-2 stations increased significantly influenced $(\mathrm{P}<0.05)$ by 2.0 and $3.3 \%$, respectively, whereas, there was no change in status of silt under control.

Clay particles did show significant differences among the sampling stations. However, clay status, at stations Q7, B3-3, C5, E6-3, R7-2, B4-3, C4, M4-3, N4, A2, D5, D5-3, H9, J9, K6-3, L7, 04, R8, A1-4, F7, I8-3, L5-3, N4-2 and R8-3 varied from 14.7 to $19.0 \%$, while it increased from 20 to $29 \%$ at stations B2, B3, C43, E6, H8, K6, K7-3, N4-3, O3, O3-3, P6-3, L7-3, K8, O5, P6, P4, P5, Q7-3, B2-3, B4, G7-3, I9, J8, J8-2, K5-3, M5, P5-3, Q6-2, L6, J8-3, N5, Q6-3, Q6, S10, S11, L5, A1-3 and G7. However, clay further increased from 30 to $36.7 \%$ at stations S9, R7, L5-2, K7, 04-3, R7-3 and P4-3, as against the control clay status of $16.7 \%$ on the surface soil.

Clay particles significantly increased in the subsurface by 37.4 and $76.4 \%$ than the surface and control stations respectively. It ranged from 21.3 to $29.0 \%$ at stations B2, C4-3, K7, R8, B2-3, D5, A2, B3-3, F7, 04-3, G7-3, H9, K5 3, M4, R7-2, A1-4, B4, B4-3, C5, E6, J8-3, L5, L7, P4, Q7, R7-3, 03, B3, D5-3, N4-3, N5, 04, P5-3, $\mathrm{P} 6, \mathrm{~S} 10$ and S11. Furthermore, clay contents ranging from 30 to $39 \%$ were identified at stations A1-3, E6-3, G7, J8, K7-3, K8, N4, 05, P5, Q6-3, R8-3, J9, H8, L7 3, N4-2, J8-2, 03-3, P4-3, L6, C4, I83, Q6, I9, and S9. On the other hand, sampling sites at L5-3, M43, M5, P6-3, K6-3, K6, Q7-3, Q6-2 and L5-2 recorded very high clay particle that varied from 40 to $53.3 \%$. Whereas the adjacent control soil recorded clay as high as $30.2 \%$ in this soil depth.

The range of values provided here; however, do not provide a good indication of the classes of soil available at the respective stations. Thus, when divided into textural classes, the following classifications were found: on the surface soil, loamy sand texture span through stations L5-3 and M4, while sandy clay covered stations K7, P4-3 and R7-3. However, sandy loam concentrated at stations A1-4, B2, J9, K6, K6-3, K7-3, L7, M4-3, N4, N4-3, O3, 03-3, 04, R7-2, R8 and R8-3. About $51.4 \%$ of the soils tend to have sandy clay loam texture that covered stations A1-3, A2, B23, B4, C5, G7, G7-3, H8, I8-3, I9, J8, J8-2, J8-3, K5 3, K8, L5, L5-2, L6, M5, N4-2, N5, 04-3, 05, P4, P5, P5-3, P6, P6-3, and Q6. Sandy loam dominated $18.6 \%$ of the field and was found at stations $\mathrm{B} 3$, B3-3, B4-3 C4, C4-3, D5, D5-3, E6, E6-3, F7, H9, L7 3 and R7, as well as the control soil.

\section{Available moisture content}

The total available water (holding) capacity is the portion of water that can be absorbed by plant roots. By definition, it is the amount of water available, stored, or released between field capacity and the permanent wilting point water contents
[9]. The average amount of total available water in the root zone for these sandy and clayey soils are indicated as 31 and $39.78 \%$ respectively. Available moisture content ranged from 25.12 to $46.0 \%$. Soil moisture content is very dependent on soil type. Saturated coarse, sandy soils shown in stations K6, J8-3, R8, R83, S9, B2, B2-3, B4, Q6-2, A1-4, R7-3, P5, 04, P6, L5, N4, G7-3, C5, E6-3, D5, P4-3 and H9, holds far less water than saturated heavy silty clay in stations 03-3, E6, Q6-3, L6, Q7, I9,03, 05, M5, S10, D5-3, G7, N4-2, P4, Q7-3, K7, N4-3, P6-3, A2, B3, K5 -3, I8-3, K8, S11, J8, J9, H8, C4, L7-3, R7, M4, P5-3, M4-3, J8-2, C4-3, B4-3, L5-3, R7-2, M4-3, and Q6. Available moisture content in coarse sandy soils varied from 25.12 to $33.60 \%$, while that of heavy clay soil ranged from 35.6 to $46 \%$, compared to $29.6 \%$ moisture in sandy loam texture at the control station. Sand has large particles which take up a lot of physical space. Also, as sand particles do not bind water, a lot of water drains out of the sand due to gravity before field capacity is reached. For these two reasons, coarse sand has much lower maximum and minimum water content than a clay soil does.

\section{Bulk density and porosity}

A measurement of the physical looseness or compaction of the soil is the soil's bulk density, weight (mass) per unit volume (which includes both the individual particles and the pore spaces). The critical value of bulk density for restricting root growth varies with soil type and management. But in general, bulk densities $>1.6 \mathrm{~g} \mathrm{~cm}^{-3}$ tends to restrict root growth [7]. However, bulk density of stations J8-2, E6, P5-3, N4-2, K5-3, 05, S11, P6-3 is scaled as loose, while stations 04-3, A1-4, B3-3, N43, 03-3, Q7, P5, Q6, D5-3, M5, L5-3, L6, R7-3, R7-2, H9, D5, C4 and R8-3 are classified as good. But the bulk density of stations L7, M4-3, J8, N4, Q7-3, 03 K7-3, N5, R8, B4-3, G7-3, J9, Q6-3, P43, S10, B3, B4, K6-3, C4-3, B2, I8-3, P4, S9, K6, I9 J8-3, G7, B2-3, 04 M4-3,C5, L5, P6, and A1-3 are scaled as firm. Whereas, bulk density of stations Q6-2, L7-3, M4, K7, F7, A2, H8, K8 and E6-3 are extremely compacted. This is important to recognize when using bulk density measurements to calculate nutrient levels and compaction on area bases to avoid an over-estimation.

On the other hand, total porosity is the measure of the volume percentage pore space. It lacks information on the degree of pore continuity which further provides useful index that gauged soil response to different management and maintenance of optimum soil aeration. Although, none of the sampling stations had poor porosity, the total porosity of stations K8, H8, E6-3, F7, A2, K7 L7-3, Q6-2, M4, A1-3 and P6 are classified unsatisfactory. Those of stations L5, M4-3, C5, 04, B2-3, J8-3 G7, I9, K6, S9, B2,P4, C43, I8-3, K6-3, B4, B3, S10, Q6-3, J9, G7-3, P4-3 B4-3 and R8 are classified as satisfactory, whereas, total porosity of stations K73, N5, O3, Q7-3, N4, J8, L7, M4-3, L5-2, R8-3, C4, D5, H9, R7-3, L6, L5-3, R7-2, M5, D5-3, Q6, P5, Q7 03-3, N4-3, B3-3, A1-4, O43, P6-3, S11, 05, K5 3, N4-2, P5-3, E6 and J8-2 are the best for optimum soil aeration. 


\section{Drainage pattern and permeability}

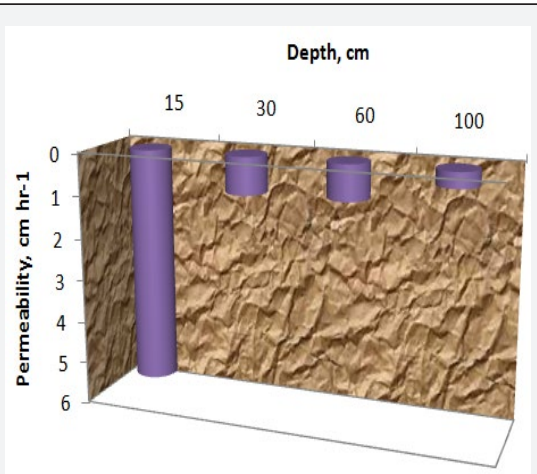

Figure 3: Showing the profile drainage pattern of fluid at different soil layers.

(Figure 3) shows that the drainage pattern at different depth varies substantially, from dominance of capillary pores on the surface to much aeration pores as it increased with depth. Under this field condition, the value of permeability $\left(5.49 \mathrm{cmhr}^{-1}\right)$ on the $0-15 \mathrm{~cm}$ soil depth met the rapid discharge limit and acceptable range for ease of remediation process. This could be explained by increase pores spaces resulting from increase in fauna counts on the surface. The lowest permeability value of $0.36 \mathrm{cmhr}^{-}$ ${ }^{1}$ representing $143 \%$ reduction from subsurface recorded at depth greater than $60 \mathrm{~cm}$ was attributed to irregular (tortuous) pathways that increased with depth. Permeability at 15-30 $\left(0.875 \mathrm{cmhr}^{-1}\right)$ and $30-60 \mathrm{~cm}\left(0.830 \mathrm{cmhr}^{-1}\right)$ soil depths, however gave significant lower permeability than the surface depth. Soil depths beyond $60 \mathrm{~cm}$ were seen to consistently superior to other depths for low permeability.

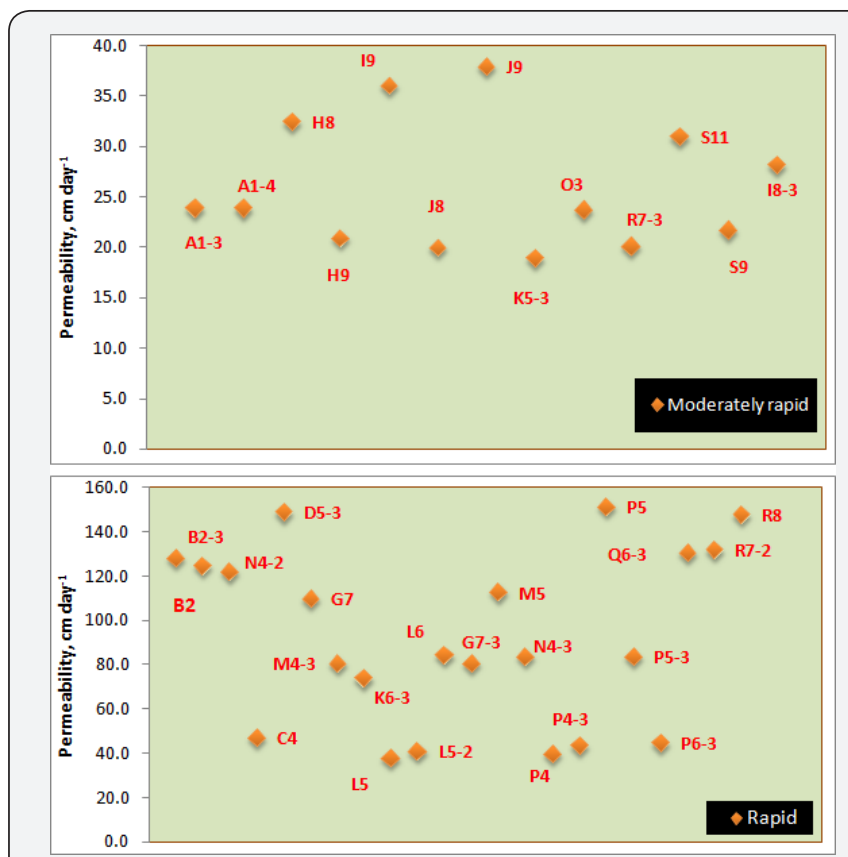

Figure 4: Showing the spatial permeability ordinations at different sampling stations.

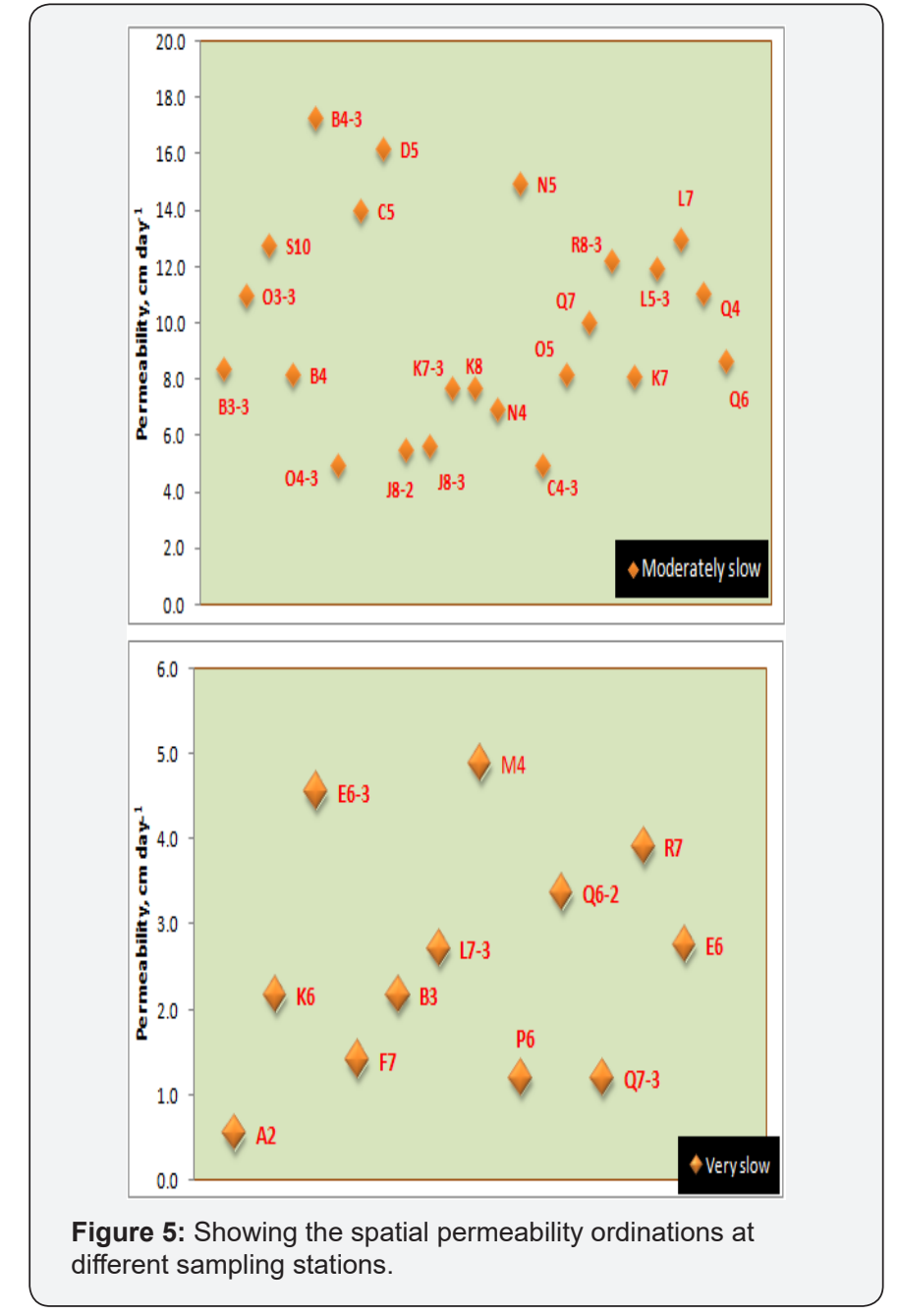

(Figure 4 \& 5) Explains the relative ease of fluid entry into the soil within the hyper space. The general trend noticed is that locations K6-3, L5, L5-2, L6, M4-3, M5, N4-2, N4-3, P4, P4-3, P5, P5-3 P6-3, Q6-3, R7-2, and R8 closer to the point of spill recorded rapid permeability per day compared to locations A2, B3, E6, E63, F7, K6, L7 3, M4, Q6-2, and Q7-3 with very slow permeability, with close proximity to river Sambrado water course, thus, distanced away from the point of spill. The explanation to this is that, oil pollution of soil leads to initial depression in the number of microorganisms present in the soil. After a certain period of adaptation to this foreign material, there is an increase in the number of hydrocarbon degraders which also increase the flow channels and in some cases several times above normal. Their numbers as affecting porosity remain high depending on the volume of spill, moisture and nutrient elements availability [10].

On the other hand, most of the impacted areas had average permeability rating ranging from moderately rapid $(19-36.1 \mathrm{~cm}$ day $^{-1)}$ to moderately slow $\left(4.9-17.3 \mathrm{~cm}\right.$ day $\left.^{-1}\right)$ permeability. Theoretically, the ratio of the height of fluid above the soil to the bulk density is the driving force, changes noticed on this field are 
brought about by soil texture and bulk density under test. It can be observed that permeability rate increases at increase in sand size and lower bulk density.

\section{Conclusion}

Findings in this study showed that the areas with high bulk density and very slow permeability revealed the direction where more rehabilitation work is expected. From agricultural and scientific points of view, oil pollution is just a temporal setback to farming processes and just how temporal is determined by the level of pollution and cleanup exercise. It must be stated, however, that during this period of temporary setback the inhabitants of the area or landowners may suffer a lot of inconveniences economically in terms of destruction and deprivation of their land from farming. A programmer of rapid rehabilitation and monitoring is necessary.

\section{References}

1. SPDC (1996) Shell petroleum Development Company. Community Issues Nigeria briefs SPDC Lagos, Nigeria.
2. Ellis R, Adams RS (1961) Contamination of soils by petroleum hydrocarbons. Adv Agron 13: 197-216.

3. Odu CT (1978) The effect of nutrient application and aeration on oil degradation in soil. Env Pollu 15: 235-240.

4. Redmond WA (2008) Encarta premium. Microsoft Corporation.

5. Udo EJ, Ibia TO, Eno JAO, Esu IE (2009) Manual of soil, plant and water analysis. Sibon Book Ltd, lagos, Nigeria.

6. Edem ID, Udo-Inyang UC (2015) Grain-size Hydraulics and Soil Characteristics in the Subtidal Site of Fertilizer Company: Grainsize Hydraulics Approach. International Letters of Natural Sciences, Switzerland, 49: 7-18.

7. Blake GR, Hartge KH (1986) Particle density in Klute. Ed methods of soil analysis. Part 1 agronomy no $9.2^{\text {nd }} d$. American society of agronomy Madison W1, pp. 363-382.

8. Hillel D (2004) Introduction to Environmental Soil Physics. Academic Press/Elsevier San Diego, USA, p. 494.

9. Brady NC, Weil RR (2013) Element of the Nature and Properties of Soils. $\left(14^{\text {th }}\right.$ edn), Prentice Hall, Upper Saddle River, Inc., New Jersey, USA.

10. Udo IUC, Edem ID, Udo MS (2015) Water use efficiency of maize variety in acid sand. Journal of Global Agriculture and Ecology 2(2): 52-58.

This work is licensed under Creative Commons Attribution 4.0 License

DOI: $10.19080 / A R T O A J .2017 .06 .555700$
Your next submission with Juniper Publishers will reach you the below assets

- Quality Editorial service

- Swift Peer Review

- Reprints availability

- E-prints Service

- Manuscript Podcast for convenient understanding

- Global attainment for your research

- Manuscript accessibility in different formats

( Pdf, E-pub, Full Text, Audio)

- Unceasing customer service

Track the below URL for one-step submission https://juniperpublishers.com/online-submission.php 